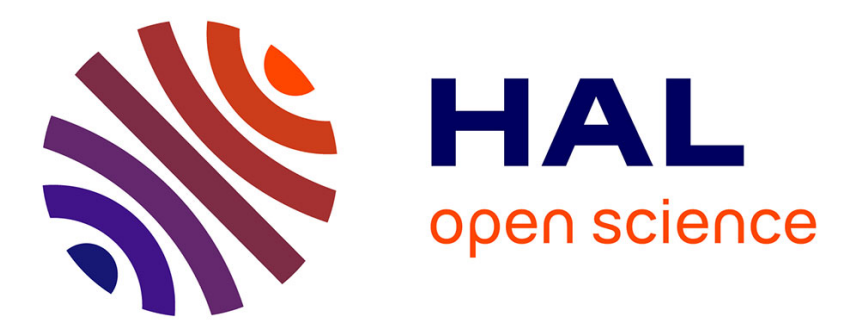

\title{
Stabilisation of heavy metal containing dusts by reaction with phosphoric acid: study of the reactivity of fly ash
}

Blandine Bournonville, Ange Nzihou, Patrick Sharrock, Guy Depelsenaire

\section{To cite this version:}

Blandine Bournonville, Ange Nzihou, Patrick Sharrock, Guy Depelsenaire. Stabilisation of heavy metal containing dusts by reaction with phosphoric acid: study of the reactivity of fly ash. Journal of Hazardous Materials, 2004, 116 (1-2), p.65-74. 10.1016/j.jhazmat.2004.07.021 . hal-01634401

\section{HAL Id: hal-01634401 https://hal.science/hal-01634401}

Submitted on 12 Nov 2019

HAL is a multi-disciplinary open access archive for the deposit and dissemination of scientific research documents, whether they are published or not. The documents may come from teaching and research institutions in France or abroad, or from public or private research centers.
L'archive ouverte pluridisciplinaire HAL, est destinée au dépôt et à la diffusion de documents scientifiques de niveau recherche, publiés ou non, émanant des établissements d'enseignement et de recherche français ou étrangers, des laboratoires publics ou privés. 


\title{
Stabilisation of heavy metal containing dusts by reaction with phosphoric acid: study of the reactivity of fly ash
}

\author{
Blandine Bournonville ${ }^{\mathrm{a}, 1}$, Ange Nzihou ${ }^{\mathrm{a}, *}$, Patrick Sharrock ${ }^{\mathrm{b}}$, Guy Depelsenaire ${ }^{\mathrm{c}}$ \\ a Laboratoire de Génie des Procédés des Solides Divisés UMR CNRS 2392, Ecole des Mines d'Albi-Carmaux, \\ Campus Jarlard, Route de Teillet, 81013 ALBI CT Cedex 09, France \\ ${ }^{\mathrm{b}}$ IUT Castres - Université Paul Sabatier, Avenue Georges Pompidou - BP 258, 81104 CASTRES Cedex, France \\ ${ }^{\mathrm{c}}$ HSE (Health, Safety, Environment), Direction Centrale Recherche et Technologie, SOLVAY, Rue de Ransbeek 310, B-1120 Bruxelles, Belgique
}

\begin{abstract}
Water-washed fly ash was reacted with phosphoric acid in order to transform available heavy metals into insoluble metal phosphate compounds. The temperature, $\mathrm{pH}$ and concentration of free phosphate were monitored during the first 80 min of reaction. Phosphoric acid reacted rapidly with second order kinetics and an apparent rate constant of $0.015 \mathrm{l} /\left(\mathrm{mol} \mathrm{s} \mathrm{m}^{2}\right)$. Analysis of the evolution of the concentrations of other major elements of fly ash shows that the reaction follows a dissolution-precipitation type mechanism. The solubility of trace heavy metals tends to increase at low $\mathrm{pH}$ values. Various heat and mass transfer coefficients are derived and help understand the phosphate stabilisation procedure and design industrial reactors for this purpose. Calcium phosphates are formed which can trap heavy metals in a stable apatite mineral structure.
\end{abstract}

Keywords: Fly ash; Phosphate reaction; Heavy metals; Stabilisation; Kinetics

\section{Introduction}

Municipal solid waste incineration (MSWI) produces large quantities of ashes. The nature of the dusts containing heavy metals is complex, and the subject of much work [1-7]. There exist variations in the chemical composition of ashes with time, with particle size and with geographical location. Modern incineration facilities are equipped with efficient scrubbers and release little atmospheric pollution [8]. Conversely, large amounts of mineral residues are formed and must be dealt with. Landfilling following a cement solidification step is becoming costly in surveillance, and new handling procedures are being sought for sustain-

\footnotetext{
* Corresponding author. Currently visiting Associate Professor at the New Jersey Institute of Technology, USA. Tel.: +33 563493 222; fax: +33 563493299

E-mail address: nzihou@enstimac.fr (A. Nzihou).

1 Present address: SDI/LPTh, CEA Le Ripault, BP 16, 37260 Monts, France.
}

able growth [5,9]. Separation of soluble and insoluble mineral species is one way to recycle chloride salts and limit heavy metal leaching from the other mineral species [10]. An industrial process reclaims sodium chloride to produce sodium bicarbonate for acid flue gas neutralisation. Waterwashed ashes can then be eliminated with a lower soluble content. To improve the inertness of water-washed ashes, a chemical treatment with phosphoric acid studied [11]. This treatment neutralises basic residues and converts heavy metal ions into insoluble phosphates. Thus, stabilisation by reaction with phosphoric acid is a promising method for beneficial reuse of incineration by-products and generally for heavy metal containing dust particles $[5,12]$. Phosphoric acid must be reacted with the dusts in such a way as to immobilise the target heavy metals, which are diluted and dispersed in a complex medium. Calcium phosphate was previously shown to immobilise heavy metals in mineral residues such as mine tailings [13,14], bottom ashes [15] or fly ashes $[10,16,17,18]$. 


\begin{tabular}{|c|c|}
\hline \multicolumn{2}{|c|}{ Nomenclature } \\
\hline$C$ & molecular concentration $\left(\mathrm{mol} / \mathrm{m}^{3}\right)$ \\
\hline$C^{\prime}$ & $\begin{array}{l}\text { specific phosphate acid concentration } \\
(453 \mathrm{mmol} / \mathrm{l})\end{array}$ \\
\hline $\mathrm{Cp}$ & heat capacity $(\mathrm{J} /(\mathrm{kg} \mathrm{K}))$ \\
\hline$d$ & characteristic diameter $(\mathrm{m})$ \\
\hline$D$ & molecular diffusivity $\left(\mathrm{m}^{2} / \mathrm{s}\right)$ \\
\hline$D^{*}$ & molecular diffusivity at infinite dilution $\left(\mathrm{m}^{2} / \mathrm{s}\right)$ \\
\hline$h$ & heat transfer coefficient $\left(\mathrm{W} /\left(\mathrm{m}^{2} \mathrm{~K}\right)\right)$ \\
\hline$k$ & apparent rate constant $\left(1 /\left(\mathrm{mol} \mathrm{s} \mathrm{m}^{2}\right)\right)$ \\
\hline$k_{\mathrm{d}}$ & mass transfer coefficient $(\mathrm{m} / \mathrm{s})$ \\
\hline$m$ & particle mass $(\mathrm{kg})$ \\
\hline$N$ & rotational speed $(1 / \mathrm{s})$ \\
\hline $\mathrm{Nu}$ & Nusselt number \\
\hline $\operatorname{Pr}$ & Prandtl number \\
\hline $\operatorname{Re}$ & Reynolds number \\
\hline$R e_{\mathrm{A}}$ & Reynolds number of agitation \\
\hline$S c$ & Schmidt number \\
\hline$S h$ & Sherwood number \\
\hline $\mathrm{Sp}$ & particle specific surface area $\left(\mathrm{m}^{2} / \mathrm{g}\right)$ \\
\hline$t$ & time $(\mathrm{s})$ \\
\hline \multicolumn{2}{|c|}{ Greek symbols } \\
\hline$\gamma$ & activity coefficient \\
\hline$\lambda$ & thermal conductivity $(\mathrm{W} /(\mathrm{m} \mathrm{K}))$ \\
\hline$\mu$ & viscosity (Pa s) \\
\hline & volumic mass $\left(\mathrm{kg} / \mathrm{m}^{3}\right)$ \\
\hline$\phi$ & agitator diameter $(\mathrm{m})$ \\
\hline \multicolumn{2}{|c|}{ Index } \\
\hline & final \\
\hline
\end{tabular}

We recently showed that phosphoric acid reacts to various degrees with calcium salts, aluminium compounds and silica [19]. Here, we present our results of the study of the reactivity of a typical fly ash with phosphoric acid. Special attention is paid to the fate of calcium and other metals during the reaction. Kinetic and thermodynamic results are presented to help understand the mechanism of the phosphoric acid chemical treatment.

\section{Experimental section}

\subsection{Materials}

Several types of ashes from flue gas filtration residues with no previous gas treatment were investigated and one illustrative case was selected. The chemical composition of the water-washed ash used in our experiments is detailed in Table 1 . The specific surface area was $15.7 \mathrm{~m}^{2} / \mathrm{g}$; the density was $2.49 \mathrm{~g} / \mathrm{cm}^{3}$ and the mean particle size $43.6 \mu \mathrm{m}$. Thermal
Table 1

Chemical composition of fly ash

\begin{tabular}{lc}
\hline $\mathrm{Al}_{2} \mathrm{O}_{3}(\%)$ & 17 \\
$\mathrm{CaO}(\%)$ & 25 \\
$\mathrm{Fe}_{2} \mathrm{O}_{3}(\%)$ & 2 \\
$\mathrm{MgO}(\%)$ & 3 \\
$\mathrm{SiO}_{2}(\%)$ & 28 \\
$\mathrm{Cl}(\%)$ & 0.9 \\
$\mathrm{~K}_{2} \mathrm{O}(\%)$ & 1.0 \\
$\mathrm{Na}_{2} \mathrm{O}(\%)$ & 1.6 \\
$\mathrm{SO}_{4}(\%)$ & 2.3 \\
$\mathrm{Loss}_{\text {of }}$ ignition & 14.4 \\
$\mathrm{Cd}(\mathrm{ppm})$ & 203 \\
$\mathrm{Cr}(\mathrm{ppm})$ & 513 \\
$\mathrm{Cu}(\mathrm{ppm})$ & 1022 \\
$\mathrm{~Pb}(\mathrm{ppm})$ & 3731 \\
$\mathrm{Zn}(\mathrm{ppm})$ & 12417 \\
\hline &
\end{tabular}

conductivities were determined by the hot disk method at $0.118 \mathrm{~W} /(\mathrm{m} \mathrm{K})$, and heat capacities with a Calvet calorimeter at $0.246 \mathrm{~kJ} /(\mathrm{kg} \mathrm{K})$. The phosphoric acid used contained $85 \%$ acid and was a viscous liquid of density $1.7 \mathrm{~g} / \mathrm{cm}^{3}$. It was purchased as a Normapur product from Prolabo.

\subsection{Methods and analytical techniques}

A closed batch reactor was used to follow phosphoric acid reaction kinetics with fly ash. It consisted in a 11 Pyrex thermostatic vessel of $10 \mathrm{~cm}$ inner diameter equipped with a stainless steel double spire helicoidal mixer of $1 \mathrm{~cm}$ width and $5 \mathrm{~cm}$ outermost diameter. The rotational speed was controlled at $400 \mathrm{rpm}$. Data acquisition was monitored with a Mettler Toledo LABMAX ${ }^{\circledR}$ instrument. Experimental parameters included temperature, $\mathrm{pH}$, time, mixing speed and mass of added phosphoric acid.

All reactions were carried out with $371.4 \mathrm{~g}$ of deionised water previously thermostated between 20 and $80^{\circ} \mathrm{C}$ during $5 \mathrm{~min}$ in the reaction vessel [20]. $200 \mathrm{~g}$ of ash was added in order to obtain a solid fraction content of $35 \%$, previously determined to be optimal for homogenous mixing by a rheological study [21]. The suspensions were homogenised during 5 min then $0,16-32 \mathrm{~g}$ of phosphoric acid were pumped in over a one-minute period. Thus, the initial phosphate concentrations were $0,453-907 \mathrm{mmol} / \mathrm{l}$. To simplify graphics, the concentration of $453 \mathrm{mmol} / 1$ will be noted $\mathrm{C}^{\prime}$ and the other concentrations will be relative to $\mathrm{C}^{\prime}$. Samples were taken regularly and filtered immediately under vacuum at $0.45 \mathrm{mi}-$ crons. During the first $5 \mathrm{~min}$, sampling intervals were $1 \mathrm{~min}$, then $2 \mathrm{~min}$ for the following $10 \mathrm{~min}$, then $5 \mathrm{~min}$ up to $60 \mathrm{~min}$. A final sample was taken at $80 \mathrm{~min}$, and the filtered solids were dried in an oven at $105^{\circ} \mathrm{C}$ for $24 \mathrm{~h}$. Reproducibility was checked several times by repeat runs.

The filtrates were sampled and analysed. Soluble phosphate was determined by UV spectrophotometry by the molybdovanadate method with a detection limit of $0.02 \mathrm{mmol} / 1$ of $\mathrm{PO}_{4}$. Chlorides and sulphates were analysed by ion chromatography and other elements by atomic absorption. 
The final solid products were examined with a Cameca SX 50 electron microprobe using a $15 \mathrm{kV}$ acceleration potential and a beam current stabilised at $12 \mathrm{nA}$. Quantitative chemical analyses of 15 elements were recorded on selected minerals using repetitive spot WDS (Wavelength Dispersion Spectrometry). The analytical conditions were adjusted to the lowest $\mathrm{Cr}, \mathrm{Pb}$ and $\mathrm{Zn}$ contents. The counting time, normally $6 \mathrm{~s}$ for major elements (Al, $\mathrm{Ca}, \mathrm{Fe}, \mathrm{K}, \mathrm{Mg}$, $\mathrm{Mn}, \mathrm{Na}, \mathrm{Si}$ and $\mathrm{Ti}$ ), was increased to $10 \mathrm{~s}$ for $\mathrm{Cl}, \mathrm{P}$ and $\mathrm{S}$, and to $20 \mathrm{~s}$ for trace elements $\mathrm{Cr}, \mathrm{Zn}$ and $\mathrm{Pb}$. The standards used were: albite- $\mathrm{NaAlSi}_{3} \mathrm{O}_{8}$ for $\mathrm{Na} \mathrm{K} \alpha$ and $\mathrm{Si} \mathrm{K} \alpha$; orthose $-\mathrm{KSi}_{3} \mathrm{AlO}_{8}$ for $\mathrm{K} \mathrm{K} \alpha ; \mathrm{Al}_{2} \mathrm{O}_{3}$ for $\mathrm{Al} \mathrm{K} \alpha ; \mathrm{MnTiO}_{3}$ for $\mathrm{Ti} \mathrm{K} \alpha$ and $\mathrm{Mn} \mathrm{K} \alpha$; andradite- $-\mathrm{Ca}_{3} \mathrm{Fe}_{2}\left(\mathrm{SiO}_{4}\right)_{3}$ for $\mathrm{Ca} \mathrm{K} \alpha$; $\mathrm{Fe}_{2} \mathrm{O}_{3}$ for $\mathrm{Fe} \mathrm{K} \alpha$; forstérite- $\mathrm{Mg}_{2} \mathrm{SiO}_{4}$ for $\mathrm{Mg} \mathrm{K} \alpha ; \mathrm{Cr}_{2} \mathrm{O}_{3}$ for $\mathrm{Cr} \mathrm{K} \alpha ; \mathrm{FeS}_{2}$ for $\mathrm{S} \mathrm{K} \alpha$; $\mathrm{PbS}$ for $\mathrm{Pb} \mathrm{M} \alpha ; \mathrm{ZnO}$ for $\mathrm{Zn}$ $\mathrm{K} \alpha$; fluoroapatite $-\mathrm{Ca}_{5}\left(\mathrm{PO}_{4}\right)_{3} \mathrm{~F}$ from Durango for $\mathrm{P} \mathrm{K} \alpha$; and vanadinite $-\mathrm{Pb}\left(\mathrm{VO}_{4}\right) \mathrm{Cl}$ for $\mathrm{Cl} \mathrm{K \alpha}$. Corrections were done with the program of Pouchou and Pichoir [22].

\section{Results and discussion}

\subsection{Temperature and $\mathrm{pH}$ evolution during phosphate reaction}

Phosphoric acid was added to a thick suspension of fly ash particles sufficiently agitated to prevent particle sedimentation. During phosphoric acid introduction, gaseous evolution was immediately observed and lasted for the first few minutes of reaction, as noted by the formation of foam on the upper surface of the suspension. Previous authors found that carbon dioxide was emitted during phosphate reaction [23].

The $\mathrm{pH}$ variations observed during phosphate reaction are illustrated in Fig. 1. Initially, the $\mathrm{pH}$ of water in contact with fly ash stabilised near $\mathrm{pH} \mathrm{10,} \mathrm{and} \mathrm{showed} \mathrm{a} \mathrm{tendency} \mathrm{to} \mathrm{de-}$ crease slowly due to carbon dioxide absorption. When phosphoric acid was added, the $\mathrm{pH}$ dropped to $\mathrm{pH} 3$ or 4 , and then slowly rose. The final $\mathrm{pH}$ depended on the amount of phosphoric acid introduced. With $453 \mathrm{mmol} / 1$ phosphoric acid, the $\mathrm{pH}$ was nearly neutral, whereas with $907 \mathrm{mmol} / 1$ phosphoric acid, the $\mathrm{pH}$ remained slightly acidic at $\mathrm{pH}$ 5.5. These $\mathrm{pH}$ values depend on the duration of mixing and correspond to previously reported values [23]. Increasing the temperature from 20 to $80{ }^{\circ} \mathrm{C}$ had little effect on the final $\mathrm{pH}$ and a small accelerating effect on the initial $\mathrm{pH}$ rise. Clearly, the $\mathrm{pH}$ is controlled by consumption of phosphoric acid, demonstrating the presence of a rapid neutralisation of the soluble bases present in fly ash, followed by a slower reaction with the suspended particles. The $\mathrm{pH}$ profile largely resembled the one found during phosphoric acid reaction with calcium carbonate, except that the $\mathrm{pH}$ is not buffered and is more sluggish [19]. Calcium hydroxide treated fly ashes were previously found to maintain a high $\mathrm{pH}$ value of 12 even after a phosphate reaction [18], and this agrees with our results concerning the reaction of phosphoric acid with pure lime [19].

The temperature changes during the experiments included a one-degree temperature rise when the fly ashes were put in suspension followed by a variable temperature increase (from 6 to $11^{\circ} \mathrm{C}$ ) depending on acid concentration. The temperature then fluctuated to reach the set value. At an initial temperature of $80^{\circ} \mathrm{C}$, the temperature rise was only $1^{\circ} \mathrm{C}$ smaller. The reaction of phosphoric acid with fly ash was exothermal with temperature jumps comprised between the values previously found for lime and limestone or melilite [19].

\subsection{Phosphate reaction kinetics}

The concentrations of soluble phosphate were monitored over the first hour of reaction. As illustrated in Fig. 2, most

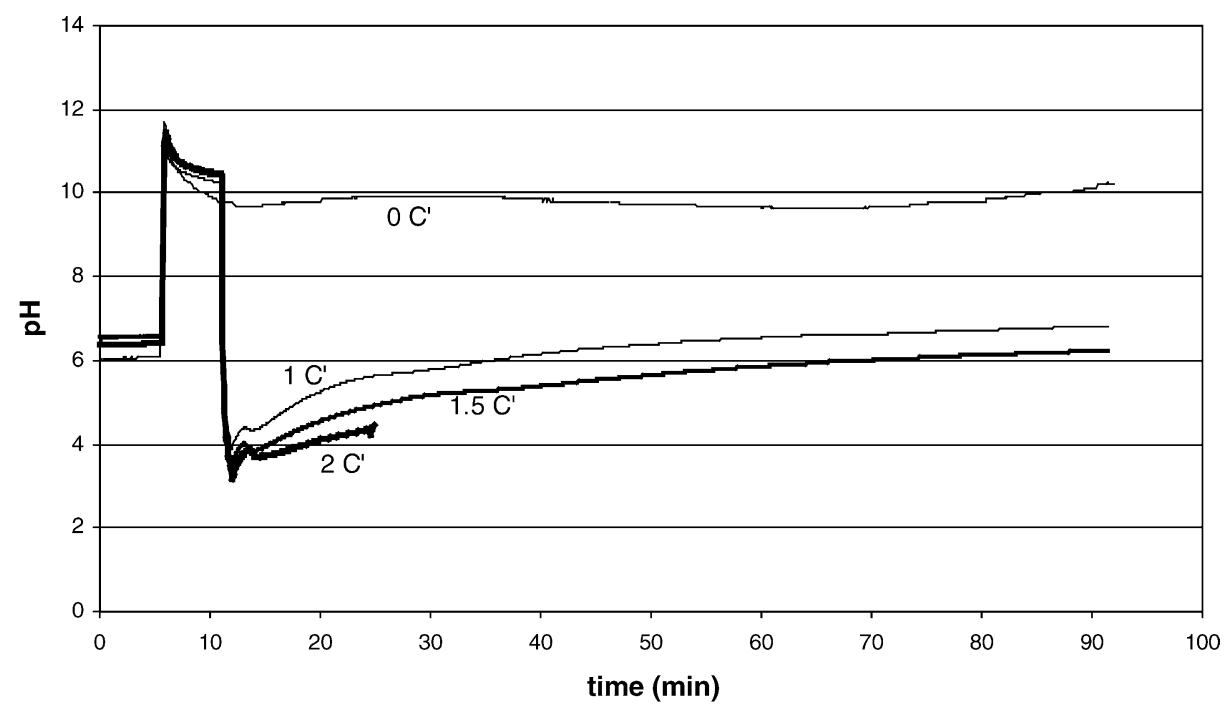

Fig. 1. $\mathrm{pH}$ of the suspension during reaction between $\mathrm{H}_{3} \mathrm{PO}_{4}$ and fly ash at $20^{\circ} \mathrm{C}, 400 \mathrm{rpm}$, and variable phosphate concentration $\left(\mathrm{C}^{\prime}: 453 \mathrm{mmol} / \mathrm{l}\right.$ of phosphoric acid). 


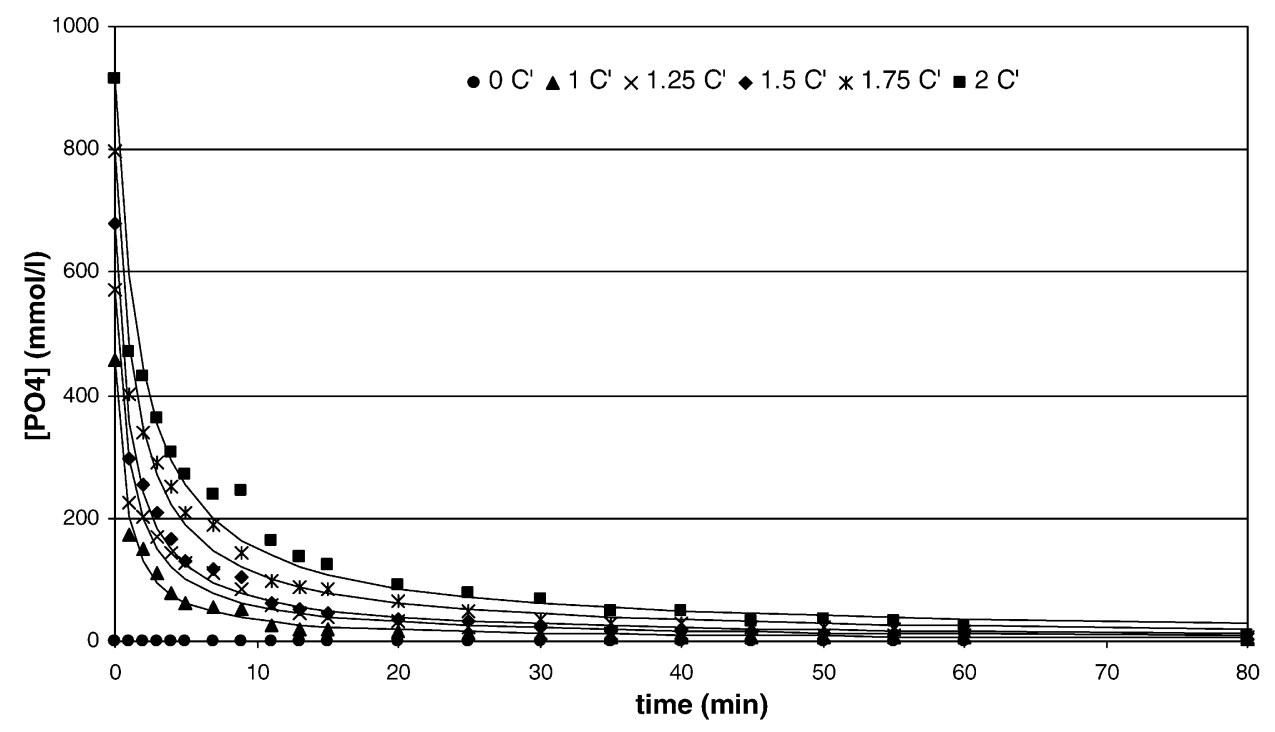

Fig. 2. $\mathrm{PO}_{4}{ }^{3-}$ in solution during reaction between $\mathrm{H}_{3} \mathrm{PO}_{4}$ and fly ash at $20^{\circ} \mathrm{C}, 400 \mathrm{rpm}$, and variable phosphate concentration $(\mathrm{C}: 453 \mathrm{mmol} / 1$ of phosphoric acid).

phosphoric acid was consumed during the first few minutes of reaction. Indeed, nearly $50 \%$ of the acid is consumed during the first minute of reaction. The reaction rate then slowed down progressively until all the soluble phosphate disappeared. Only $1.3 \%$ residual phosphate could be found at the end, always less than $12 \mathrm{mmol} / \mathrm{l}$. The time needed to consume the phosphate depended on initial concentrations introduced. In general, 50\% were consumed during the first minute, $40 \%$ during the next $10-30 \mathrm{~min}$ and the last $10 \%$ within an hour. In comparison to our results on phosphoric acid reactivity with isolated compounds, the reaction rates observed were slower revealing a more complex situation [19].

When the phosphate reaction was carried out at higher temperatures, the observed reaction rates were faster, as shown in Fig. 3, which is in agreement with the Arrhenius law. The general appearance did not change, however, and the same trend was noted with rapid phosphate concentration decrease during the first minutes of reaction. In our case, the acid was supposed to be homogeneously distributed within the suspension and rapidly formed insoluble compounds by precipitation. The usual nucleation step preliminary to solids formation can be skipped because of the high concentration of suspended particles. Crystal formation can then be thought of as occurring by diffusion of acid molecules in the solution up to the surfaces of the solids followed by a surface reaction step during which the molecules actually react and integrate the crystalline solid.

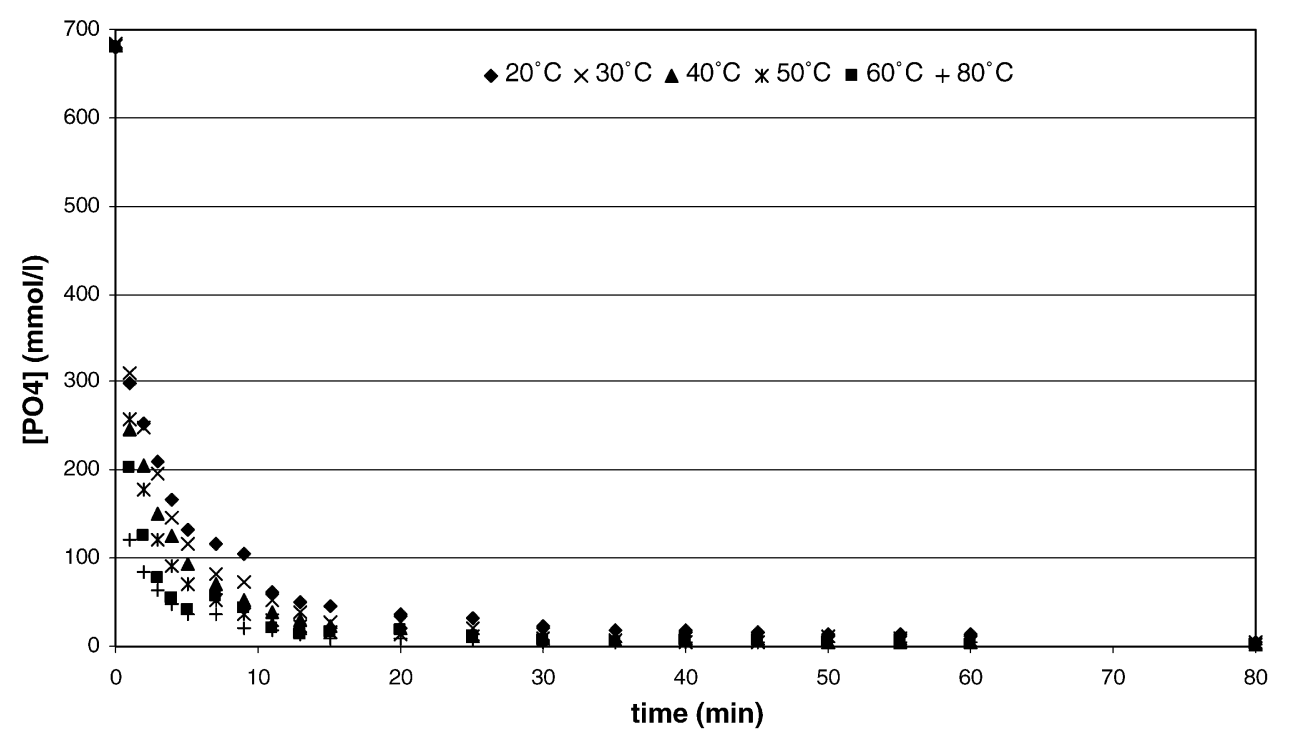

Fig. 3. $\mathrm{PO}_{4}{ }^{3-}$ in solution during reaction between $\mathrm{H}_{3} \mathrm{PO}_{4}$ and fly ash at variable temperature, $400 \mathrm{rpm}$, and phosphate concentration of $1.5 \mathrm{C}^{\prime}\left(\mathrm{C}^{\prime}: 453 \mathrm{mmol} / 1\right.$ of phosphoric acid). 


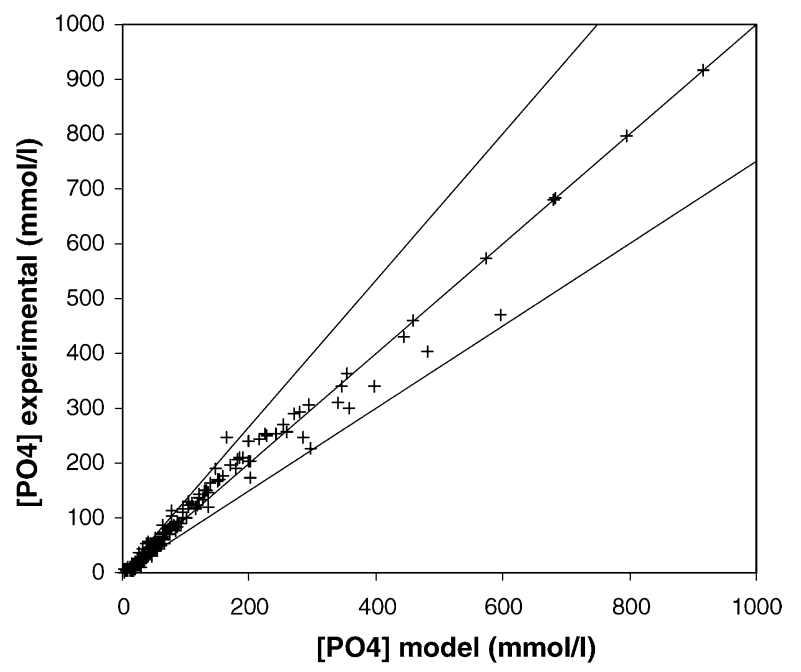

Fig. 4. Comparison between model and experiment $( \pm 25 \%$ deviation range $)$.

Experimentally, we followed free phosphate concentrations and soluble calcium concentrations as a function of reaction time. For phosphoric acid, the data fitted the following equation Eq. (1), where the final concentration is in fact that found at $80 \mathrm{~min}$,

$-\frac{\mathrm{d}\left[\mathrm{PO}_{4}\right]}{\mathrm{d} t}=k \times \mathrm{Sp} \times m \times\left(\left[\mathrm{PO}_{4}\right]-\left[\mathrm{PO}_{4}\right]_{\mathrm{f}}\right)^{2}$

where $\mathrm{Sp}$ is the initial specific surface area, $m$ the mass of fly ash and $k$ is the apparent rate constant. The specific surface area and mass of fly ash should change with increasing reaction time and only the initial known values are used for comparative reasons.

The kinetic data are presented in Fig. 2 showing the experimental results and the calculated curves for phosphate concentration as a function of time. The differences between the calculated and experimental values are illustrated in Fig. 4, showing adequate correspondence within a maximum deviation range of $25 \%$. Second order kinetics gave the best results. It should be noted that the acid reactant is not introduced at once but over a one minute starting period. The apparent reaction rate constant varies with temperature and with the percentage of acid introduced in the initial mixture. The variations in the rate constant values are plotted in Fig. 5. The data shows slower reaction rates at higher phosphate concentrations, with a rate constant of $0.015 \mathrm{l} /\left(\mathrm{mol} \mathrm{s} \mathrm{m}^{2}\right)$ for $453 \mathrm{mmol} / 1$ phosphoric acid, dropping to $0.0031 /\left(\mathrm{mol} \mathrm{s} \mathrm{m}^{2}\right)$ for $907 \mathrm{mmol} / \mathrm{l}$ phosphoric acid. This can be explained by the formation of an insoluble precipitate on the surface of the particles, which slows the diffusion of phosphate to the core of the reacting solids. The increase in rate constant as a function of temperature obeys the Arrhenius law. The derived activation energy is $21.8 \mathrm{~kJ} / \mathrm{mol}$, a small value comparable to that of $15.8 \mathrm{~kJ} / \mathrm{mol}$ determined previously for the reaction between calcium carbonate and phosphoric acid [19]. This favours a simple mechanism for the reaction, such as neutralisation and precipitation.
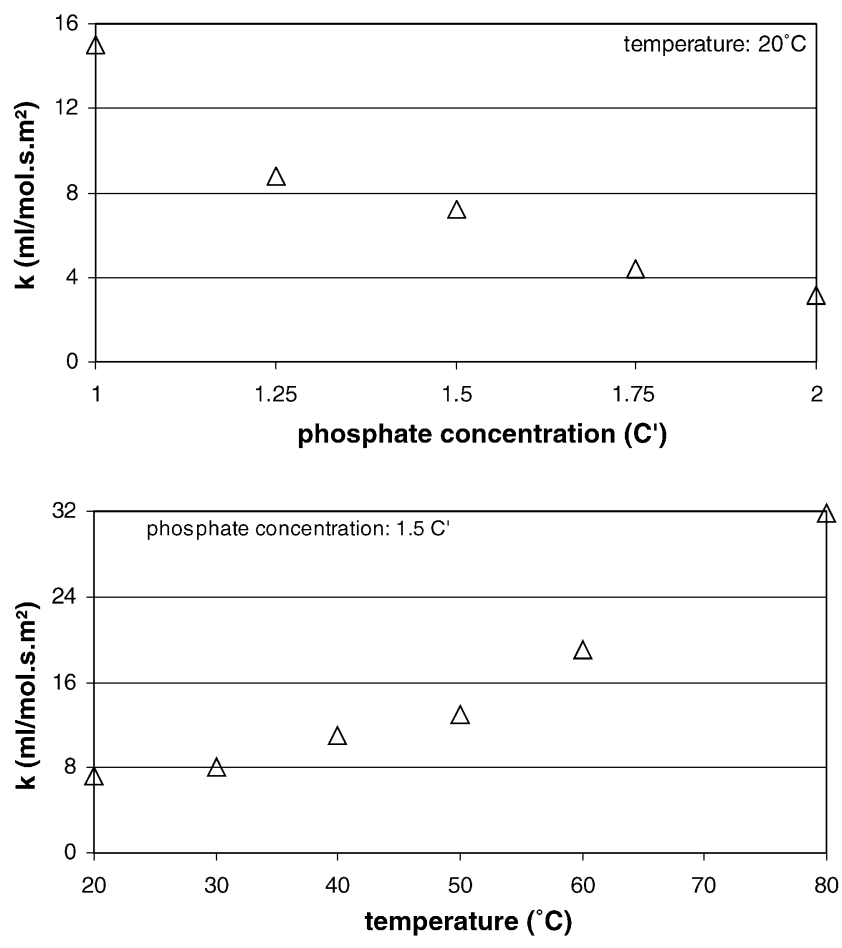

Fig. 5. Reaction rate constant value evolution $\left(\mathrm{C}^{\prime}: 453 \mathrm{mmol} / 1\right.$ of phosphoric acid).

\subsection{Heat of reaction}

Similar experiments were carried out in adiabatic conditions to determine the heat of reaction [24]. During the reaction, two factors contribute to the total heat of reaction: the heat of dilution of the acid and the actual heat of reaction. It should be noted that in our case, the fly ash particles are previously water-washed and therefore no heat of hydration is to be considered. Moreover, fly ash was water suspended $5 \mathrm{~min}$ prior to phosphate reaction to equilibrate the temperature. Using $4.18 \mathrm{~kJ} /(\mathrm{kg} \mathrm{K})$ for the heat capacity of water and $1.48 \mathrm{~kJ} /(\mathrm{kg} \mathrm{K})$ for that of phosphoric acid, and the experimentally derived heat of dilution of the acid in water under adiabatic conditions, we found an enthalpy of dilution for

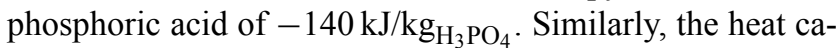
pacity of fly ash was determined to be $0.246 \mathrm{~kJ} /(\mathrm{kg} \mathrm{K})$. For the various concentrations of acid used, the heat released was between 5.5 and $11 \mathrm{~kJ}$. Thus, the global enthalpy of the reaction was $-685 \mathrm{~kJ} / \mathrm{kg}_{\mathrm{H}_{3} \mathrm{PO}_{4}}$ with a phosphoric acid "neutralisation" enthalpy of $-545 \mathrm{~kJ} / \mathrm{kg}_{\mathrm{H}_{3} \mathrm{PO}_{4}}$.

\subsection{Mass and heat transfer mechanism}

The fly ash particles studied did not show intra particle porosity. In fact, the investigation of the porosity using Mercury porosimetry and conventional BET methods did not show the evidence of pores in fly ash particles. The high specific surface area of fly ash particles could be caused by the micropores that we do not investigated in this study. Therefore molecular diffusion of phosphoric acid or Knudsen diffusion 
refering respectively to macroporous and microporous media could not be considered in our study. In practice, mass transfer coefficients are estimated with semi empirical correlations, which require knowledge of the diffusion coefficient in the fluid film surrounding the particles. Characteristic transfer values can be derived based on some assumptions: the particles are spherical, the system is isotherm, and agitation allows homogeneous dispersion of the particles.

The mass transfer is related by the Sherwood number, $S h=2+0.6 R e^{1 / 2} S c^{1 / 3}$. The Sherwood number is also expressed as follows, $S h=k_{\mathrm{d}} d / D$; the Schmidt number is $\mathrm{Sc}=$ $\mu / \rho D$.

The heat transfer is related by the Nusselt number [25], $N u=2+0.6 \operatorname{Re}^{1 / 2} \operatorname{Pr}^{1 / 3}$. The Nusselt number is also expressed as follows, $N u=h d / \lambda$; and the Prandtl number is $P r=C p \mu / \lambda$. The Reynolds number $R e$ is taken as the Reynolds number of agitation expressed by $\operatorname{Re}_{\mathrm{A}}=\rho N \phi^{2} / \mu$.

The diffusion coefficient at infinite dilution is determined from the equivalent molar ionic conductivity. For non-ideal solutions, Fick's law is established as a function of activity coefficient, and the diffusion coefficient for a given species is expressed as:

$D=D^{*}\left(1+C \frac{\mathrm{d} \ln \gamma}{\mathrm{d} C}\right)$

where $D$ is the molecular diffusivity $\left(\mathrm{m}^{2} / \mathrm{s}\right), D^{*}$ the molecular diffusivity at infinite dilution $\left(\mathrm{m}^{2} / \mathrm{s}\right), C$ the molecular concentration $\left(\mathrm{mol} / \mathrm{m}^{3}\right)$, and $\gamma$ is the activity coefficient.

Keeping in mind that the $\mathrm{pH}$ remains between 3 and 7 , the major form of phosphoric acid is the anionic species $\mathrm{H}_{2} \mathrm{PO}_{4}{ }^{-}$. Thus, $D^{*}$ is $9.59 \times 10^{-10} \mathrm{~m}^{2} / \mathrm{s}$. Other characteristics of the suspension (density, heat capacity and thermal conductivity) were determined experimentally or derived from data on the constituents (thermal conductivity of water is $0.607 \mathrm{~W} /(\mathrm{m} \mathrm{K})$ ). Dimensionless numbers determined for fly
Table 2

Mass and heat transfer characteristics of the suspension of fly ash

Re 12

$\begin{array}{ll}\text { Sc } & 2,155,031\end{array}$

Sh 271

$\begin{array}{lr}\text { Pr } & 13,246\end{array}$

$\mathrm{Nu}$

$k_{\mathrm{d}}(\mathrm{m} / \mathrm{s})$

51

$3.5 \times 10^{-6}$

$h\left(\mathrm{~W} /\left(\mathrm{m}^{2} \mathrm{~K}\right)\right)$

448

ash particles suspended at $35(\mathrm{wt} \%)$ in water with $680 \mathrm{mmol} / \mathrm{l}$ phosphoric acid are presented in Table 2. The low Reynolds number of 12 reveals laminar flow for the suspension. A value of $S h \gg 1$ is obtained indicating that external mass transfer resistance is negligible. This was confirmed by variable speed mixing tests. Constant mixing speed and variable mixing speeds were compared for the $680 \mathrm{mmol} / 1$ phosphoric acid reactions. Starting at $400 \mathrm{rpm}$, then changing to $600 \mathrm{rpm}$ after $5 \mathrm{~min}$ of reaction and then $800 \mathrm{rpm}$ after $20 \mathrm{~min}$ of reaction had no effect on the reaction rate. In fact, no evident change in slope was observed in the free $\mathrm{PO}_{4}{ }^{3-}$ concentration decay curves. This showed that diffusion of soluble phosphate ions in the liquid film surrounding the particles is not the rate-controlling factor [26]. The limiting kinetic step is to be found in the chemical reaction with the suspended particles. The mass transfer coefficient derived from the Sherwood number is of $3 \times 10^{-6} \mathrm{~m} / \mathrm{s}$ for the fly ash. This low value indicates that diffusion in the liquid film is not entirely negligible. However, diffusion is not the limiting step as confirmed by the low values found for the activation energies. As for heat transfer, large Prandtl and Nusselt numbers reflect conduction-convection control for heat transport and diffusivity. The heat transfer coefficient indicates that the fluid phase has adequate capacity to remove heat released by the reaction [27]. In an industrial application, the phosphoric acid reaction with fly ash should be straightforward.

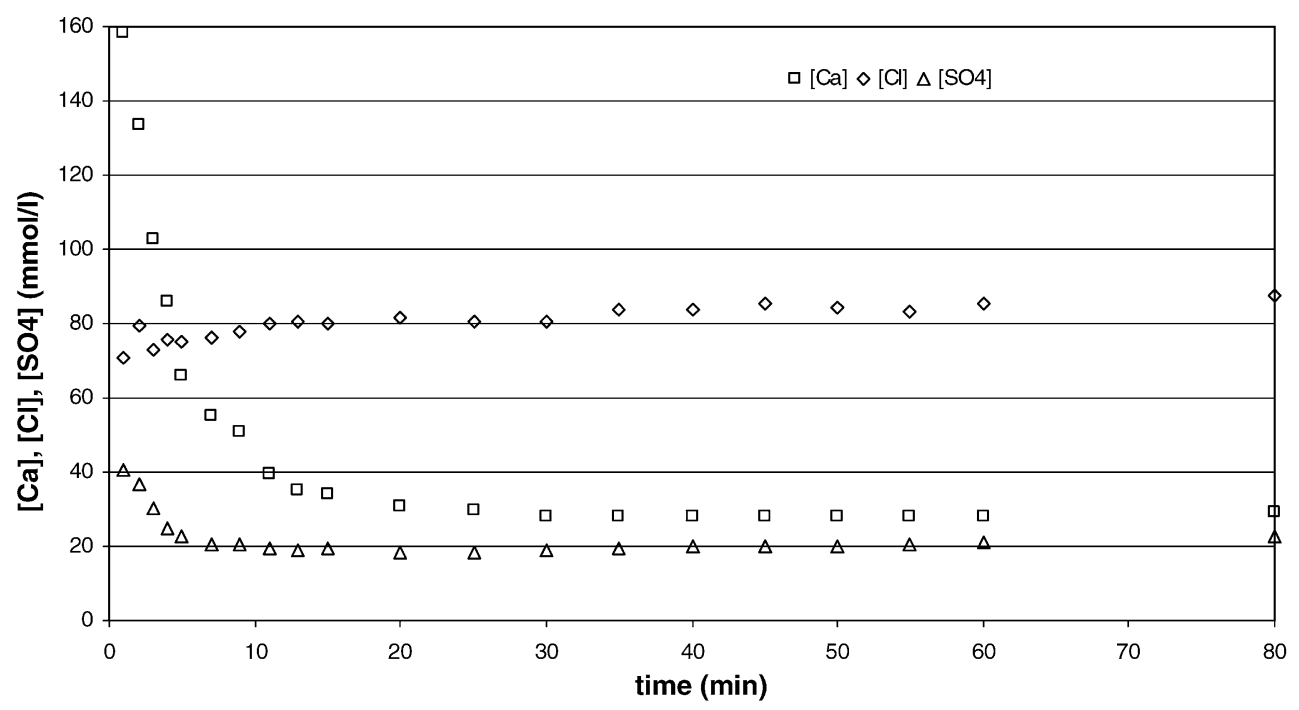

Fig. 6. $\mathrm{Ca}^{2+}, \mathrm{Cl}^{-}$and $\mathrm{SO}_{4}{ }^{2-}$ in solution during reaction between $\mathrm{H}_{3} \mathrm{PO}_{4}$ and fly ash at $20{ }^{\circ} \mathrm{C}, 400 \mathrm{rpm}$, and phosphate concentration of $1.5 \mathrm{C}^{\prime}\left(\mathrm{C}^{\prime}: 453 \mathrm{mmol} / 1\right.$ of phosphoric acid). 


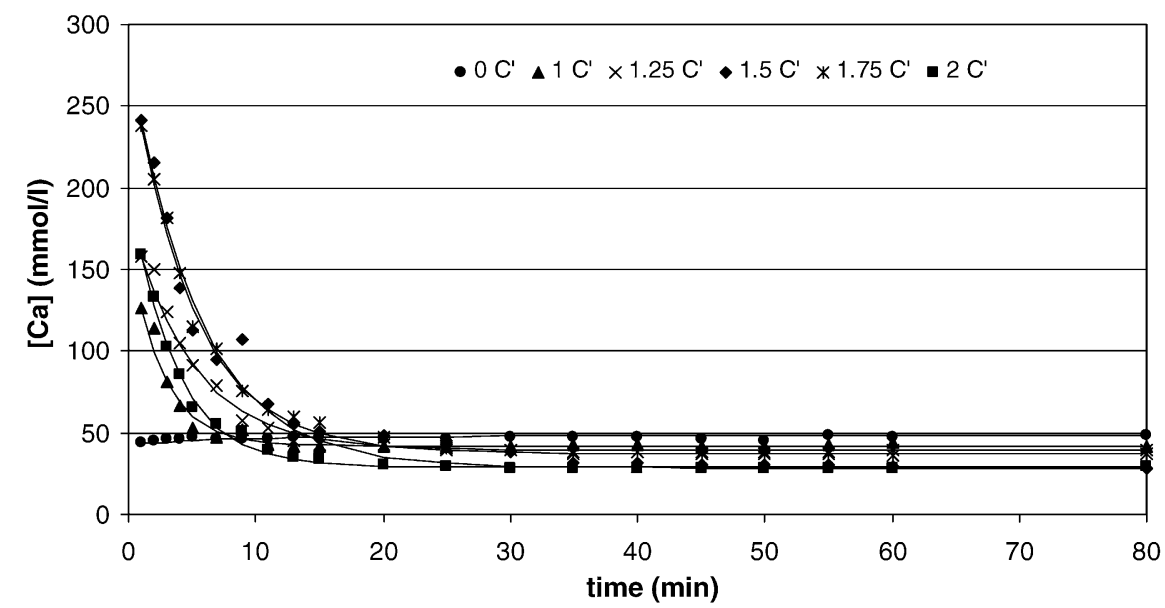

Fig. 7. $\mathrm{Ca}^{2+}$ in solution during reaction between $\mathrm{H}_{3} \mathrm{PO}_{4}$ and fly ash at $20^{\circ} \mathrm{C}, 400 \mathrm{rpm}$, and variable phosphate concentration $\left(\mathrm{C}^{\prime}: 453 \mathrm{mmol} / 1\right.$ of phosphoric acid).

The kinetics of the reaction of some elements of fly ash were also investigated to better understand the phosphate reaction mechanism.

\subsection{Reaction kinetics of some major elements of fly ash}

Following the concentrations of other elements in solution during the phosphate reaction can shed light on the processes occurring while the acid is being consumed. We followed calcium, chloride, sulphate and chromium concentrations during the reaction of fly ash. The results presented in Fig. 6 show that the soluble chloride concentration tended to slowly increase with time, while for the other elements the concentrations decreased progressively. The chromium concentrations were very low $(>0.1 \mathrm{mmol} / 1$ with $0.001 \mathrm{mmol} / 1$ detection limit) and are not apparent on the $\mathrm{mmol} / \mathrm{l}$ scale. Interestingly, the initial soluble calcium contents were small $(45 \mathrm{mmol} / \mathrm{l})$ and during the first minute of acid introduction, when the $\mathrm{pH}$ dropped below $\mathrm{pH} 4$, soluble calcium actually increased. Calcium is, therefore, dissolved by the acid before precipitating as an insoluble compound. Monitoring the calcium concentrations as a function of time (see Fig. 7) and fitting the experimental results to a first order theoretical equation Eq. (2) yielded rate constant values varying from $5 \times 10^{-7}$ to $100 \times 10^{-7} 1 /\left(\mathrm{s} \mathrm{m}^{2}\right)$.

$-\frac{\mathrm{d}[\mathrm{Ca}]}{\mathrm{d} t}=k \times \mathrm{Sp} \times m \times\left([\mathrm{Ca}]-[\mathrm{Ca}]_{\mathrm{f}}\right)$

At the end of the phosphate reaction, the final calcium concentrations were very low and reached $27 \mathrm{mmol} / 1$, two times less than the initial equilibrium concentration of calcium in phosphate free fly ash. This is in agreement with the known behaviour of calcium and phosphoric acid and the expected precipitation of calcium phosphates near neutral $\mathrm{pH}$ values. Further results presented in Fig. 8 related to the temperature dependence of the calcium reaction allowed the determination of an activation energy of $20.0 \mathrm{~kJ} / \mathrm{mol}$ according to the Arrhenius equation. Similarly, low energy barriers were found in the reactions of phosphoric acid with calcium salts [19].

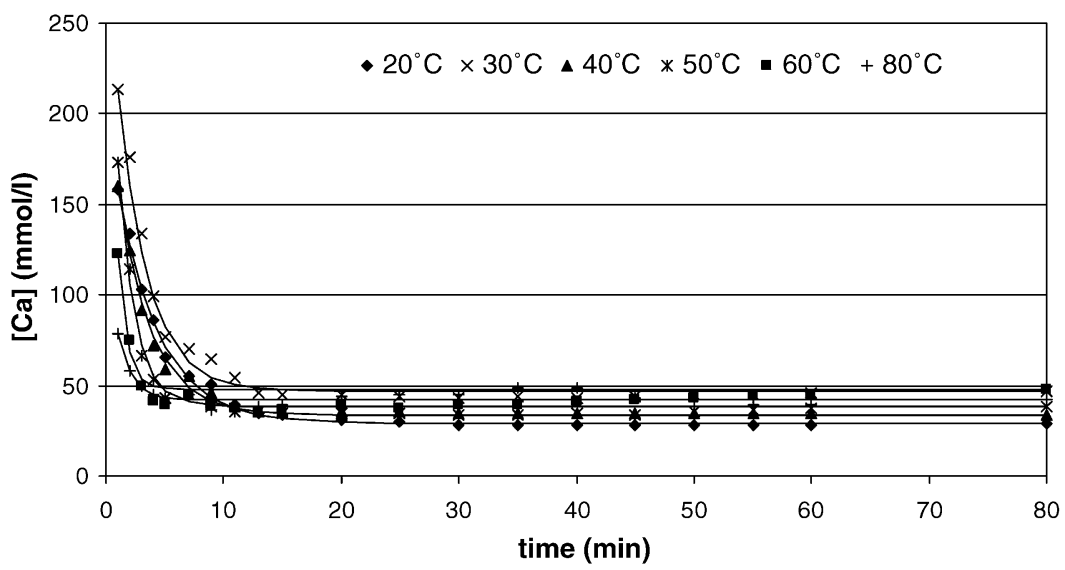

Fig. 8. $\mathrm{Ca}^{2+}$ in solution during reaction between $\mathrm{H}_{3} \mathrm{PO}_{4}$ and fly ash at variable temperature, $400 \mathrm{rpm}$, and phosphate concentration of $1.5 \mathrm{C}^{\prime}\left(\mathrm{C}^{\prime}: 453 \mathrm{mmol} / 1\right.$ of phosphoric acid). 


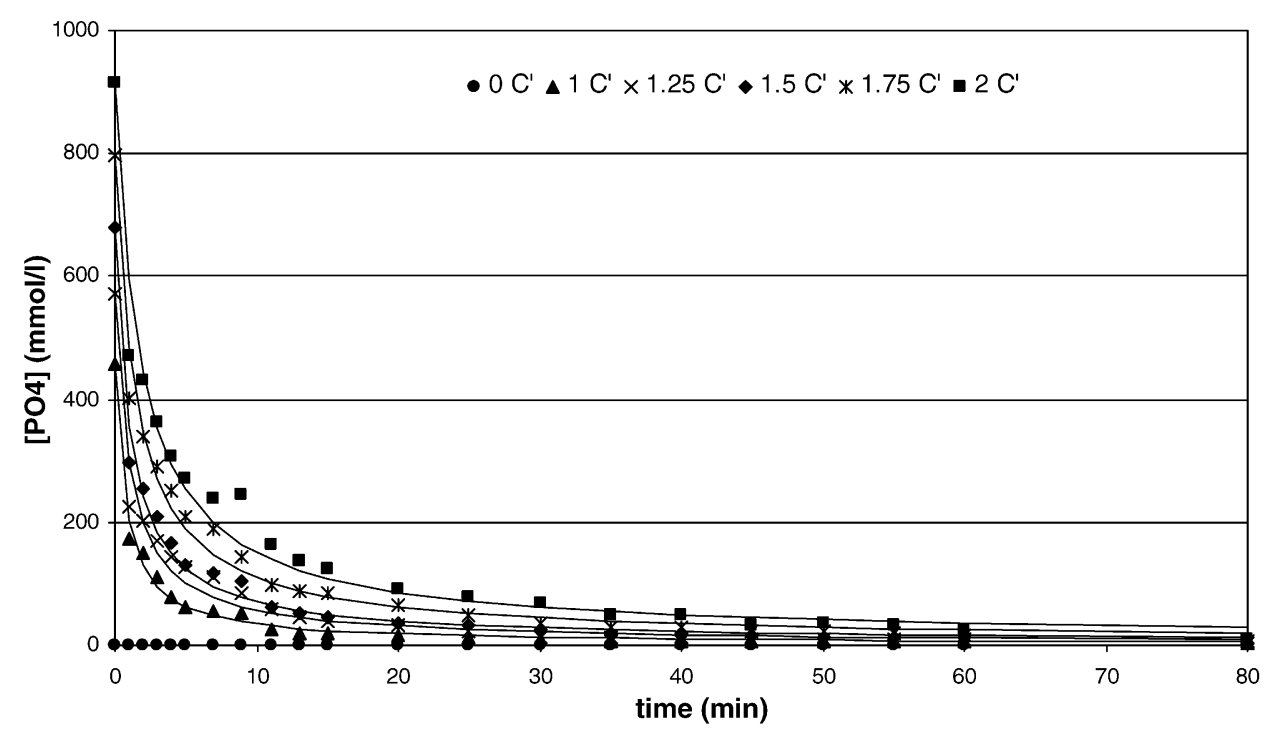

Fig. 9. Chromium in solution during reaction between $\mathrm{H}_{3} \mathrm{PO}_{4}$ and fly ash at variable temperature, $400 \mathrm{rpm}$, and phosphate concentration of $1.5 \mathrm{C}^{\prime}\left(\mathrm{C}^{\prime}: 453 \mathrm{mmol} / 1\right.$ of phosphoric acid).

The solubility behaviour of chloride and sulphate can be interpreted in terms of the initial presence of chlorides and sulphates of limited solubility. Only little $\mathrm{Cl}$ remained present in the initial water-washed ashes and part of it could dissolve yielding the observed values. Acidification of the suspension of fly ash liberated cations present in the solid particles. A new equilibrium was then reached with more soluble alkali chlorides and less soluble divalent metal ion sulphates and phosphates. An analogous scheme can be invoked to explain the variations in soluble chromium. Chromium is not known to precipitate with phosphates, but poorly soluble chromates are formed with divalent cations including calcium. During the first minute of phosphate reaction, chromium concentrations rose by a 10-fold factor, and then slowly decreased to reach an equilibrium value lower than the soluble chromium concentration without added phosphate. This precipitation reaction lasted nearly $15 \mathrm{~min}$ and was found to be temperature sensitive (see Fig. 9). The kinetic study showed second order behaviour with rate constants between 0.02 and $1.41 /\left(\mathrm{mol} \mathrm{s} \mathrm{m}^{2}\right)$, and a relatively large activation energy of $108 \mathrm{~kJ} / \mathrm{mol}$.

None of the experiments performed with variable mixing speed showed any signs of diffusion-controlled reaction. The rate limiting steps are therefore the chemical reactions leading to the formation of insoluble precipitates. The same experiment was carried out replacing fly ash by a silicoaluminate of melilite type highly contaminated with chromium. It was found that melilite consumed less than $75 \%$ of the phosphoric acid and chromium was stable between 0.4 and $1 \mathrm{mmol} / 1$. So, chromium included in the silicoaluminate melilite does not react with phosphoric acid [20]. Thus, chromium precipitates with other ions present in fly ash and leached by the acid treatment.

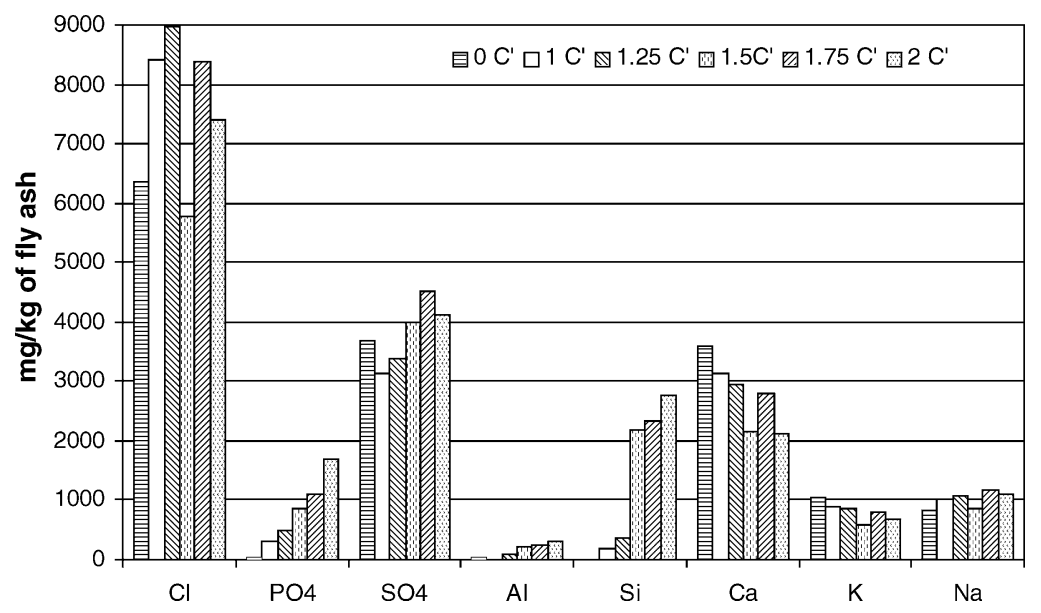

Fig. 10. Major components of fly ash in solution after $80 \mathrm{~min}$ reaction between $\mathrm{H}_{3} \mathrm{PO}_{4}$ and fly ash at $20^{\circ} \mathrm{C}, 400 \mathrm{rpm}$, and variable phosphate concentration (C': $453 \mathrm{mmol} / \mathrm{l}$ of phosphoric acid). 


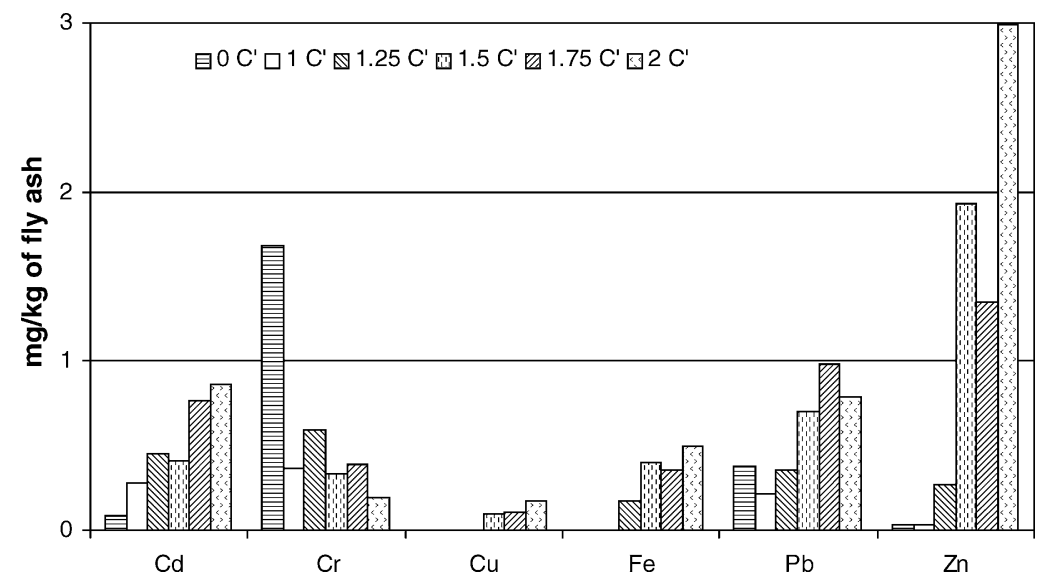

Fig. 11. Heavy metals in solution after $80 \mathrm{~min}$ reaction between $\mathrm{H}_{3} \mathrm{PO}_{4}$ and fly ash at $20^{\circ} \mathrm{C}, 400 \mathrm{rpm}$, and variable phosphate concentration $\left(\mathrm{C}^{\prime}: 453 \mathrm{mmol} / 1\right.$ of phosphoric acid).

Following the $80 \mathrm{~min}$ reaction period, the suspensions were filtered and the solutions analysed for soluble ions. The results for the major species of fly ash are presented in Fig. 10. Among the anions, residual phosphate increased with the amount of phosphoric acid introduced in the reactor, reflecting the yet incomplete nature of the reaction at this time. Chlorides and sulphates tended to dissolve slightly with twice as much chloride ( $8000 \mathrm{mg} / \mathrm{kg}$ fly ash) as sulphate (4000 mg/kg fly ash). Alkali levels remained low for sodium and potassium at $1000 \mathrm{mg} / \mathrm{kg}$ fly ash. Dissolved aluminium and silica increased with increasing amounts of phosphoric acid. On the other hand, calcium concentrations decreased with phosphoric acid. Temperature effects were evaluated and revealed that residual $\mathrm{Si}, \mathrm{Al}$ and $\mathrm{PO}_{4}$ decreased with increasing temperature, whereas $\mathrm{Na}$ increased slightly and $\mathrm{K}$, $\mathrm{Ca}, \mathrm{Cl}$ and $\mathrm{SO}_{4}$ remained constant (data not shown). In any case, the results show that phosphoric acid reacted rapidly during the first few minutes but that further transformation of species continued slowly thereafter.

The behaviour of trace elements is illustrated in Fig. 11. As explained above, chromium concentrations decreased when phosphoric acid increased. However, for $\mathrm{Cd}, \mathrm{Cu}, \mathrm{Fe}, \mathrm{Pb}$ and $\mathrm{Zn}$, the concentrations of soluble metals were low but tended to increase with phosphoric acid. It should be reminded that these concentrations were found at the end of the $80 \mathrm{~min}$ reaction periods studied. It seems logical that an acid treatment should modify soluble element distributions because of $\mathrm{pH}$ effects, and that the final mobility of heavy metals should depend on the nature of the solids formed at the end of the process including water evaporation.

\subsection{Final product composition}

The microprobe analysis of reacted fly ash confirmed that the initial soluble phosphate was indeed precipitated onto the solid phase (Fig. 12). Most of the phosphate formed seems to be associated with calcium. The $\mathrm{Ca} / \mathrm{P}$ ratio observed between 1 and 1.7 is related to the formation of species such as

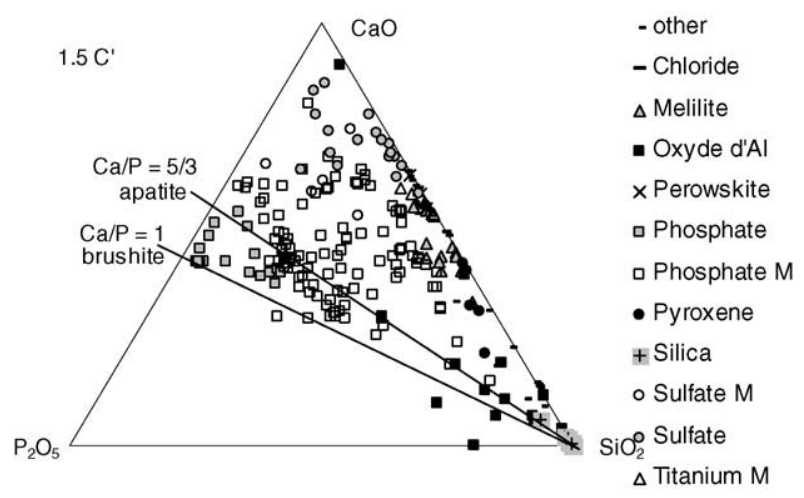

Fig. 12. Triangular $\mathrm{CaO}-\mathrm{P}_{2} \mathrm{O}_{5}-\mathrm{SiO}_{2}$ diagram for treated fly ash (M: mix).

brushite and apatite. Due to thermodynamic considerations brushite will be transformed into an apatite phase with time and/or heat. Apatites can form solid solutions with heavy metals, which are consequently stabilised as complex orthophosphates. The reaction of fly ash with phosphoric acid is therefore an efficient way to displace heavy metals from a soluble phase to a less soluble solid. More results on these aspects will be presented in another report on speciation and further mineralogical identifications.

\section{Conclusions}

The kinetics of solubility changes for several products (phosphate, calcium, chromium) were followed during the reaction of fly ash with phosphoric acid. The data fitted a classical dissolution-precipitation type equation with second order kinetics for phosphate and chromium and first order kinetics for calcium. The activation energies were similar for phosphate and calcium (near $20 \mathrm{~kJ} / \mathrm{mol}$ ) and higher for chromium $(100 \mathrm{~kJ} / \mathrm{mol})$. This reaction formed calcium phosphates as final products, which are reported to trap heavy metals $[5,10,13]$. 
The expected result of phosphate treatment of fly ash is the stabilisation of heavy metals. Our results support the proposal that a complex matrix involving calcium hydroxylapatite like phosphates of low solubility is the major phosphate end product. Many similarities exist between the phosphoric acid reaction with fly ash and with calcium carbonate or hydroxide. Despite the complex nature of the reactions, which occur with phosphoric acid, it can be claimed that the acid treatment affects trace heavy metals and leads with time to their inclusion in stable insoluble divalent metal phosphate minerals.

\section{Acknowledgement}

This work was supported by SOLVAY Group (Health Safety Environment Department). This support is gratefully acknowledged.

\section{References}

[1] L. Le Forestier, G. Libourel, Environ. Sci. Technol. 32 (15) (1998) 2250-2256.

[2] J.D. Eudsen, T.T. Eighmy, K. Hockert, E. Holland, K. Marsella, Appl. Geochem. 14 (1999) 1073-1091.

[3] T.T. Eighmy, B.S. Crannell, J.E. Krzanowski, L.G. Butler, F.K. Cartledge, E.F. Emery, J.D. Eusden Jr., E.L. Shaw, C.A. Francis, Waste Manage. 18 (1998) 513-524.

[4] R. Derie, Chim. Nouvelle 10 (37) (1992) 1091-1097.

[5] P. Piantone, F. Bodénan, R. Derie, G. Depelsenaire, Waste Manage. 23 (3) (2003) 225-243.

[6] N. Delville, J.M. Montel, P. Boivin, G. Torrent, MIOM 2001 - Quel avenir pour les MIOM?, Orléans, France, 2001.

[7] S. Fendeleur, G. Trouvé, L. Delfosse, Déchets - Sci. Tech. 12 (1998) 21-26.

[8] A. Blouet, Décision Environnement - Cahier technique 35 (1995) I-V.

[9] E.F. Barth, J.J. Barich, in: J.M. Cases, F. Thomas (Eds.), Actes du congrès international sur les Procédés de Solidification et de Stabilisation des déchets, Nancy, France, 1995, pp. 391394.

[10] A. Nzihou, P. Sharrock, Waste Manage. 22 (2002) 235-239.

[11] R. Derie, Waste Manage. 16 (8) (1996) 711-716.

[12] A. Vaquier, B. Husson, J. Verdier, S. Julien, Stab. Env. 99 (1999) 359-364.

[13] J.D. Eudsen Jr., L. Gallagher, T.T. Eighmy, B.S. Crannell, J.R Krzanowski, L.G. Butler, F.K. Cartledge, E.F. Emery, E.L. Shaw, C.A. Francis, Waste Manage. 22 (2002) 117-135.

[14] T.T. Eighmy, J.D. Eudsen Jr., L. Gallagher, B.S. Crannell, J.R. Krzanowski, Stab. Env. 99 (1999) 26-29.

[15] B.S. Crannell, T.T. Eighmy, J.E. Krzanowski, J.D. Eusden Jr., E.L. Shaw, C.A. Francis, Waste Manage. 20 (2000) 135-148

[16] M.R. Lyons, in: T. Telford (Ed.), Sustainable construction: use of incinerator ash, Concrete Technology Unit, University of Dundee, UK, 2000, pp. 87-96.

[17] T.T. Eighmy, B.S. Crannell, L.G. Butler, F.K. Cartledge, E.F. Emery, D. Oblas, J.E. Krzanowski, J.D. Eusden Jr., E.L. Shaw, C.A. Francis, Environ. Sci. Technol. 31 (11) (1997) 3330-3338.

[18] T. Ushida, I. Itoh, K. Harada, Waste Manage. 16 (5-6) (1996) 475-481.

[19] B. Bournonville, A. Nzihou, P. Sharrock, G. Depelsenaire, Trans IChemE Part B, submitted for publication.

[20] B. Bournonville, Stabilisation des métaux lourds dans les cendres volantes d'incinération - Comportement rhéologique, cinétique de phosphatation et évaluation du procédé. Thesis, Université de Perpignan, 2002.

[21] B. Bournonville, A. Nzihou, Powder Technol. 128 (2-3) (2002) 148-158.

[22] J.L. Pouchou, J.F. Pichoir, Quantitative analysis of homogeneous or stratified micro-volume applying the model "PAP", Plenum, New York, USA, 1991.

[23] R. Derie, C. Depaus, Stab. Env. 99 (1999) 269-273.

[24] B. Bournonville, S. Bailliez, A. Nzihou, P. Sharrock, Beneficial use of recycled materials in transportation applications, Air and Waste Management Association, Arlington, VA, USA, 2001, February 2003, pp. 791-800.

[25] A. Zoulalian, Techniques de l'ingénieur, J1300 (1989) 1-28.

[26] S. Chiarle, M. Ratto, M. Rovatti, Water Res. 34 (11) (2000) 2971-2978.

[27] A. Nzihou, B. Bournonville, P. Marchal, L. Choplin, Trans IChemE Part A, Chem. Eng. Res. Des. 82 (A5) (2004) 637-641. 